\title{
HIV-1 subtypes among intravenous drug users from two neighboring cities in São Paulo State, Brazil
}

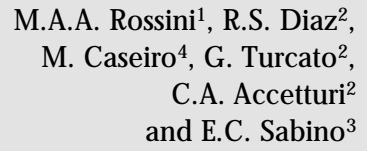

\author{
${ }^{1}$ Instituto Adolfo Lutz, ${ }^{2}$ Laboratório de Retrovirologia, \\ Escola Paulista de Medicina, Universidade Federal de São Paulo, and \\ ${ }^{3}$ Fundação Pró-Sangue/H emocentro de São Paulo, São Paulo, SP, Brasil \\ ${ }^{4}$ Centro de Referência de AIDS (CRAIDS), Santos, SP, Brasil
}

\begin{abstract}
\section{Correspondence}

R.S. Diaz

Laboratório de Retrovirologia

EPM, UNIFESP

R. Pedro de Toledo, 781

04039-000 São Paulo, SP

Brasil

Fax: + 55-11-570-8226/571-2130

E-mail: rsdiaz@usp.br

Publication supported by FAPESP.

Received May 8, 2000

Accepted November 8, 2000

In order to assess the molecular epidemiology of HIV-1 in two neighboring cities located near the epicenter of the HIV-1 epidemics in Brazil (Santos and São Paulo), we investigated 83 HIV-1 strains obtained from samples collected in 1995 from intravenous drug users. The V3 through V5 region of the envelope of $g p 120$ was analyzed by heteroduplex mobility analysis. Of the 95 samples, 12 (12.6\%) were PCR negative (6 samples from each group); low DNA concentration was the reason for non-amplification in half of these cases. Of the 42 typed cases from São Paulo, 34 (81\%, 95\% confidence limits 74.9 to $87.0 \%)$ were B and 8 (19\%, 95\% confidence limits 12.9 to $25.0 \%)$ were F, whereas of the 41 typed cases from Santos, 39 (95\%, 95\% confidence limits 91.6 to $98.4 \%)$ were B and 2 (5\%, $95 \%$ confidence limits 1.6 to $8.4 \%$ ) were $\mathrm{C}$. We therefore confirm the relationship between clade $\mathrm{F}$ and intravenous drug use in São Paulo, and the presence of clade $\mathrm{C}$ in Santos. The fact that different genetic subtypes of HIV-1 are co-circulating indicates a need for continuous surveillance for these subtypes as well as for recombinant viruses in Brazil.
\end{abstract}

\section{Key words}

- HIV-1 subtypes

- Intravenous drug users

- Molecular epidemiology

- Heteroduplex mobility analysis

- Brazil
A total of 128,821 clinical cases of AIDS had been reported in Brazil up to February 1998 , and it is estimated that as many as 580,000 individuals are currently infected with HIV (1). Almost $72 \%$ of the reported cases were from the southeast region of the country, with São Paulo city accounting for $25 \%$ of them (1). The distribution of AIDS incidence in 1996 and 1997 among various groups was $24 \%$ among homo-bisexual males, $20.2 \%$ among intravenous drug users (IDU), 32.5\% among heterosexual individuals with known sexual exposure, and 23.3\% among individuals with unknown transmis- sion route. As is the case for many developing countries, more than one co-circulating clade of HIV-1 are present in Brazil. Overall, the predominant strain is clade $\mathrm{B}$, accounting for $90 \%$ of the characterized strains, clade $\mathrm{F}$ accounts for $5-8 \%$, and clades $C$ and $D$ represent less than $2 \%$ of the total (2-6).

In a previous study we suggested that subtype F was related to IDU in Brazil (5). In the latter study, however, only a few cases of IDU and their sexual partners from an AIDS clinic in São Paulo city were available. In the present study, we not only expanded the survey of the IDU population from São Paulo 
city, but also accessed the IDU population of Santos, a city located $60 \mathrm{~km}$ from São Paulo. Santos is a port city with a very high prevalence of HIV infection, where as many as $61 \%$ of the infected individuals are IDUs. We prospectively analyzed a total of 95 consecutive samples collected from HIV-1-infected IDUs: 48 patients attending an outpatient AIDS clinic at the Federal Medical University of São Paulo and 47 from the outpatient clinics of the Reference Center for AIDS in Santos. In both centers, mean patient age was 33 years, and $18 \%$ of them were females. Samples were collected in 1995. Peripheral blood mononuclear cells were obtained after saponin lysis of whole blood, digested with proteinase-K, and subjected to alcohol precipitation for DNA isolation. Amplification of a portion of the env gene was carried out by nested PCR, and the resulting fragment was used for HIV-1 subtyping by heteroduplex mobility analysis (7).

Of the 95 samples, 12 (12.6\%) were PCR negative (6 samples from each group), with low DNA concentration being the reason for non-amplification in half of these cases. Of the 42 typed cases from São Paulo, 34 (81\%) were $\mathrm{B}$ and $8(19 \%)$ were $\mathrm{F}$, whereas of the 41 typed cases from Santos, 39 (95\%) were

Table 1 - Distribution of HIV-1 subtypes in São Paulo and Santos (Brazil).

Subtype was determined by heteroduplex mobility analysis. The prevalence of subtype $F$ was higher in São Paulo than in Santos $(P=0.002$, chisquare test).

\begin{tabular}{lllll}
\hline City & \multicolumn{3}{c}{ Subtype profile, N (\%) } & \multirow{2}{*}{ Total } \\
\cline { 2 - 4 } & \multicolumn{1}{c}{ B } & \multicolumn{1}{c}{ C } & \multicolumn{1}{c}{ F } \\
\hline São Paulo & $34(81)$ & 0 & $8(19)$ & 42 \\
Santos & $39(95)$ & $2(5)$ & 0 & 41 \\
Total & $73(88)$ & $2(2.4)$ & $8(9.6)$ & 83
\end{tabular}

$\mathrm{B}$ and $2(5 \%)$ were $\mathrm{C}$ (Table 1). One of the individuals from Santos, subtyped as $\mathrm{C}$, was HIV positive since 1986, suggesting that this virus has been circulating in Brazil for a long time. Therefore, our results confirm a high prevalence of clade $\mathrm{F}$ in the IDU population of São Paulo, but not of its neighbor city of Santos, although the sampling size of this study is still limited.

According to Leitner (8), phylogenetic analysis of HIV-1 subtypes suggests that the epidemic evolved in two phases; an early phase, in which the virus spread more slowly between host groups in Africa, generating a network of variants, and a more recent and still ongoing phase, in which a particular variant of the virus reached and spread rapidly in naive populations. This is the socalled "founder effect" which is responsible for the vast preponderance of subtype B circulating in Europe and in the Americas. The next phase of the epidemic will likely be dynamic competition between the prevalent co-circulating strains present in some regions of the world. Some strains may prevail, either due to different inherent biological properties of the viruses or to epidemiological host reasons. It is now recognized that clade E overwhelmed clade B in the IDU population in Thailand (9), and that clade $\mathrm{C}$ is expanding out of proportion in Africa (10).

The distribution of HIV subtypes in Brazil seems to be quite complex since their prevalence may differ significantly even between neighboring cities where the epidemic started at about the same time. It will be important to monitor the HIV subtype profiles in Brazil during the next phase of the epidemic, when competition among clades is expected to occur, bearing in mind that the distribution of subtypes has local determinants, and that data from one site cannot be generalized to the entire country or even to a single geographic region. 


\section{References}

1. Ministério da Saúde do Brasil (1997). AIDS Boletim. Setembro a Novembro, Ano $X$ (No. 4).

2. Potts KE, Kalish ML, Lott T, Orloff G, Luo $C C$, Bernard MA, Alves CB, Badaro R, Suleiman J , Ferreira O, Schochetman G, J ohnson J r WD, Ou C-Y, Ho J L \& the Brazilian Collaborative AIDS Research Group (1993). Genetic heterogeneity of the V3 region of the HIV-1 envelope glycoprotein in Brazil. AIDS, 7: 1191-1197.

3. Morgado MG, Sabino EC, Shpaer EG, Bongertz $V$, Brigido $L$, Guimarães $M D$, Castilho EA, Galvão-Castro B, Mullins J I, Hendry RM \& Mayer A (1994). V3 region polymorphisms in HIV-1 from Brazil: prevalence of subtype $B$ strains divergent from North American/European prototype and detection of subtype F. AIDS Research and Human Retroviruses, 10: 569576.

4. WHO Network for HIV Isolation and Characterization (1994). HIV-1 variation in WHO-sponsored vaccine evaluation sites: Genetic screening, sequence analysis and preliminary biological characterization of representative viral strains. AIDS Research and Human Retroviruses, 10: 1927-1943.

5. Sabino EC, Diaz RS, Brigido LF, Leam GH, Mullins JI, Reingold AL, Duarte AJ S, Mayer A \& Busch MP (1996). Distribution of HIV-1 subtypes seen in an AIDS clinic in São Paulo city, Brazil. AIDS, 10: 15791584.

6. Morgado $M G$, Guimarães $M L$, Gripp $C B$, Costa Cl, Neves J r I, Veloso VG, LinharesCarvalho MI, Castello-Branco LR, Bastos FI, Kuiken C, Castilho EA, Galvão-Castro B \& Bongertz V (1998). Molecular epidemiology of HIV in Brazil: High prevalence of B subtype and identification of an HIV-1 subtype $D$ infection in Rio de J aneiro city. J ournal of Acquired Immune Deficiency Syndromes and Human Retrovirology, 18: 488-494.

7. Delwart EL, Shpaer EG, Louwagie J, McCutchan FE, Grez M, RubsamenWaigmann H \& Mullins J I (1993). Genetic relationships determined by a DNA het- eroduplex mobility assay: analysis of HIV1 env genes. Science, 262: 1257-1261.

8. Leitner T (1996). Genetic subtypes of HIV1. Human retroviruses and AIDS 1996. A compilation and analysis of nucleic acid and amino acid sequences. Los Alamos National Laboratory, Los Alamos, III28III 40 .

9. Renjifo B, Chaplin B, Mwakagile D, Shah $P$, Vannberg F, Msamanga G, Hunter D, Fawzi W \& Essex M (1998). Epidemic expansion of HIV type 1 subtype $C$ and recombinant genotypes in Tanzania. AIDS Research and Human Retroviruses, 14: 635-638.

10. Kalish ML, Baldwin A, Raktham S, Wasi C, Luo CC, Schochetman G, Mastro TD, Young N, Vanichseni $S$ \& RubsamenWaigmann H (1995). The envolving molecular epidemiology of HIV-1 envelope subtypes in injecting drug users in Bankok, Thailand: implication for HIV vaccine. AIDS, 9: 851-857. 